\title{
Upward Fire Growth over Thermally Thin Corrugated Paperboard
}

\author{
MOHAMMED M. KHAN, K.L.T. JAMISON, and JOHN L. DE RIS \\ FM Global, Research Division \\ 1151 Boston-Providence Turnpike \\ Norwood, Massachusetts 02062 USA
}

\begin{abstract}
A simple analytical model is developed for fire growth of thermally-thin corrugated paperboard in a parallel panel configuration that simulates the vertical flues between stored commodities in a rack storage arrangement. It is based on a semi-empirical model for radiation-dominated flame heat transfer to panels in terms of: (1) fuel flame sootiness, (2) fire heat release rates, and (3) panel width to separation aspect ratios. The model input properties include: heat of combustion, minimum heat of gasification, yield of smoke, and critical heat flux obtained from the fire propagation apparatus. The effect of moisture on fire growth rate is incorporated in the model. The predictions of the model are compared with experimental data on the rate of chemical heat release measured for the upward fire growth of vertical corrugated paperboard samples $(0.305 \mathrm{~m} \times 2.4 \mathrm{~m})$ placed opposite one another in a parallel panel configuration $(0.153 \mathrm{~m}$ apart $)$. The model predictions of exponential fire growth time constant agree reasonably well with the experimentally determined values. Because of an enhanced role of convective heat transfer for parallel panels with $0.153 \mathrm{~m}$ separation distance, an adjustment of radiation constant $\beta_{1}$ was needed for reasonable prediction of fire growth time constant. For a fixed geometry, the model prediction of fire growth time constant depends on the material properties and moisture content.
\end{abstract}

KEYWORDS: fire growth, corrugated paperboard, thermally thin, parallel panels.

\section{NOMENCLATURE LISTING}

$\begin{array}{llll}c_{0} & \text { specific heat of dry corrugated paper }(\mathrm{kJ} / \mathrm{kg} \cdot \mathrm{K}) & \dot{q}_{0}^{\prime \prime} & \text { surface heat loss rate }\left(\mathrm{kW} / \mathrm{m}^{2}\right) \\ c_{p w} & \text { specific heat of water }(\mathrm{kJ} / \mathrm{kg} \cdot \mathrm{K}) & T_{b} & \text { boiling point of water }(\mathrm{K}) \\ \Delta H_{c} & \text { effective heat of combustion }(\mathrm{kJ} / \mathrm{g}) & T_{i g} & \text { surface ignition temperature }(\mathrm{K}) \\ \Delta H_{g} & \text { heat of gasification }(\mathrm{kJ} / \mathrm{g}) & T_{0} & \text { ambient temperature }(\mathrm{K}) \\ d & \text { separation distance of panels }(\mathrm{m}) & w & \text { width of each panel }(\mathrm{m}) \\ \ell_{p} & \text { pyrolysis length }(\mathrm{m}) & Y_{s} & \text { fuel smoke yield }(\mathrm{g} / \mathrm{g}) \\ \ell_{f} & \text { flame length }(\mathrm{m}) & Y_{g} & \text { gas equivalent smoke yield }(\mathrm{g} / \mathrm{g}) \\ L_{w} & \text { heat of vaporization of water }(\mathrm{kJ} / \mathrm{kg}) & \mathbf{G r e e k} & \\ m^{\prime \prime} & \text { mass of dry corrugated per unit area }\left(\mathrm{kg} / \mathrm{m}^{2}\right) & \alpha & =d / w \text {, aspect ratio }(-) \\ m_{w} & \text { fractional added mass of water in the sample }(-) & \beta_{1} & \text { radiation constant }(-) \\ \dot{q}_{c h}^{\prime \prime \prime} & \text { chemical heat release rate per unit volume } & \beta_{2} & \text { heat loss constant }(-) \\ \dot{q}_{c h}^{\prime \prime} & \left.\text { chW/m }{ }^{3}\right) & \sigma & \text { Stephan-Boltzmann }\left(\mathrm{kW} / \mathrm{m}^{2} \mathrm{~K}^{4}\right) \\ \dot{q}_{f}^{\prime \prime} & \text { flame heat flux }\left(\mathrm{kW} / \mathrm{m}^{2}\right) & \varsigma_{f} & \ell_{f} / w(-) \\ \dot{q}_{c r}^{\prime \prime} & \quad \text { critical heat flux for ignition }\left(\mathrm{kW} / \mathrm{m}^{2}\right) & \tau_{i g} & \text { ignition time }(\mathrm{s}) \\ F_{s w \rightarrow s w} & \text { view factor between side wall to side wall } & \tau_{g} & \text { fire growth time constant }(\mathrm{s})\end{array}$

\section{INTRODUCTION}

Fires often spread very rapidly up vertical surfaces presenting one of the most hazardous fire scenarios of fire protection engineering. The rapidity of the fire growth is due to co-flowing flame gases directly heating unburned fuel elements and bringing them rapidly to ignition adding more fuel to the fire. The fire growth may also become exceedingly challenging depending on the geometric arrangement of the materials. For 
example, warehouse commodities are typically stored in corrugated paperboard containers arranged in rack configuration. As a result, they form flue spaces between containers, simulating a parallel panel configuration, where the upward fire growth generally increases exponentially in time, creating a hazardous fire situation with potential consequences for fire growth to the adjacent commodities. The rate of fire growth thus significantly impacts the fire protection requirements. Also, depending on the time of the year, the absorption/drying of moisture in ambient air by the hygroscopic corrugated paperboard material is an important factor in its fire growth behavior, which can make the difference between controlling and not controlling a fire with a given sprinkler system.

There are several models [1-7] for upward fire spread over thermally-thick and thin materials burning as a single surface. Each of these models predicts exponentially growing fire intensity while presuming, of course, that the fuel is sufficiently large and capable of supporting self-sustaining fire spread. Alpert [8] showed that both point ignition sources as well as line sources produce exponentially growing fires spreading over vertical panels of PMMA. Karlsson [9] developed a general model for upward fire spread predicting the extent of fire propagation over thermally-thick materials that are not fully capable of selfsustained fire spread. Heskestad [10] developed a well known set of characteristic $t$-squared fire growth curves for various fires spreading horizontally with heat release rates growing with the square of time. The curves are for crib fires and warehouse storage and other such similar situations after the fire has reached the top of the fuel array. Finally, Khan et al. [11] evaluated flame propagation over large-scale thin polymeric non-melting skylight materials based on measurements, in a small-scale apparatus, of ignition time, burning duration and heat release rate. None of the above models apply an independent model for the flame heat transfer. Also none apply to the more hazardous parallel panel situation.

FM Global's current CFD fire modeling effort addresses the problem of large-scale fires in complex geometries, such as rack storage fires with the objective of reducing the number of large-scale tests needed to develop fire protection requirements [12]. As a first step toward achieving that goal, an intermediatescale Parallel Panel Apparatus [13] was used to test single wall corrugated paperboard samples mounted on two $0.6 \mathrm{~m}$ wide and $2.4 \mathrm{~m}$ high panels (separation between panels is $0.305 \mathrm{~m}$ ) with a $60 \mathrm{~kW}$ sand burner at the bottom of the panels. It was shown that the CFD simulation results are in general quantitative agreement with the experimental data for heat release rate, heat fluxes and temperatures of the solid fuel surfaces [14]. Material properties required by the pyrolysis model are extracted using the same model and a specially developed optimization technique to fit the experimental data obtained using the fire propagation apparatus (ASTM E2058, FPA) [15].

In the present study, we develop a simple analytical model for fire growth over thermally-thin corrugated paperboard in a parallel panel configuration that simulates the vertical flues between stored commodities in a rack storage arrangement. The model is based on a semi-empirical treatment for radiation dominated flame heat transfer to panels characterized by: (1) fuels in terms of their flame sootiness, (2) fire heat release rates, and (3) panel width to separation aspect ratios [16]. The properties of the various corrugated paperboards used in the study (critical heat flux, flame sootiness in addition to the heats of combustion and gasification) are all obtained from small-scale measurements of ignition, combustion and pyrolysis using the FPA. The objective of the model is to predict the exponential growth time constant including the effects of moisture [17] for the various types of corrugated paperboard.

The results are compared with experimental measurements of the actual growth time constants for the same corrugated paperboard arranged in a $2.4 \mathrm{~m}$ high and $0.3 \mathrm{~m}$ wide parallel panel arrangement with $0.153 \mathrm{~m}$ separation between the panels. This configuration simulates the flue space between the corrugated paperboard boxes in rack storage. A $15 \mathrm{~kW}$ propane sand burner placed in direct contact below the samples initiated the fires. The test configuration provides sufficient size and confinement of flames for yielding realistic flame heat transfer, while giving the flames ready access to air entering from the sides.

\section{ANALYTIC FIRE GROWTH MODEL}

The proposed fire growth model is simple and is based on five assumptions:

1. Volumetric flame heat release is constant given by $\dot{q}_{c h}^{\prime \prime \prime}=1100 \mathrm{~kW} / \mathrm{m}^{3}$ [16].

2. The flame remains confined between parallel panels simulating corrugated paperboard and maintains a rectangular shape having height $\ell_{f}$, width $w$ and depth $d$. See Fig. 1 . 


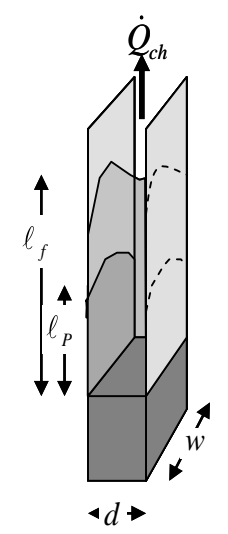

Fig. 1. Model parameters.

3. The flame heat flux $\dot{q}_{f}^{\prime \prime}$ is given by the general empirical correlation for flames between parallel panels [16].

4. The corrugated paperboard ignites as either a thermally-thin or thermally-thick solid depending on the imposed flame heat flux and ignitability as measured in the FPA [17].

5. Once ignited the corrugated paperboard continues to burn without burning out.

The overall rate of chemical heat release rate is given by

$\dot{Q}_{c h}=\ell_{f} w d \dot{q}_{c h}^{\prime \prime \prime}=2 \ell_{p} w \dot{q}_{c h}^{\prime \prime}$

Here $\dot{q}_{c h}^{\prime \prime}$ is the chemical heat release rate per unit area of the pyrolyzing solid when subjected to the flame heat flux, $\dot{q}_{f}^{\prime \prime} ; \ell_{f}$ and $\ell_{p}$ are the flame length and the pyrolysis length, respectively; $w$ and $d$ are the width of each panel and panel separation distance, respectively. Using the effective heat of combustion, $\Delta H_{c}$ and the heat of gasification, $\Delta H_{g}$ one has

$$
\dot{q}_{c h}^{\prime \prime}=\left(\dot{q}_{f}^{\prime \prime}-\dot{q}_{0}^{\prime \prime}\right) \Delta H_{c} / \Delta H_{g}
$$

where $\dot{q}_{0}^{\prime \prime}$ is surface heat loss rate due to re-radiation from the wall material being tested. Solving Eq. 1 for the flame height, one has

$$
\ell_{f}=\frac{\dot{Q}_{c h}(t)}{w d \dot{q}_{c h}^{\prime \prime \prime}}=\frac{2 \ell_{p} \dot{q}_{c h}^{\prime \prime}}{d \dot{q}_{c h}^{\prime \prime \prime}}
$$

We assume that the flame heat transfer to the corrugated is uniform up to the height $\ell_{\text {f }}$. The corrugated paperboard begins to pyrolyze at time $\tau_{i g}$ after arrival of the flames at a particular height. That is, as time increases from time $t$ to time $t+\tau_{i g}$ the pyrolysis height increases from $\ell_{p}$ to $\ell_{f}$. This is expressed by the equation

$$
\frac{d \ell_{p}}{d t}=\frac{\ell_{f}-\ell_{p}}{\tau_{i g}} .
$$

Substituting Eq. 3 for $\ell_{p}$ one has 
$\frac{d \ell_{p}}{d t}=\left[\frac{2 \dot{q}_{c h}^{\prime \prime}}{d \dot{q}_{c h}^{\prime \prime \prime}}-1\right] \frac{\ell_{p}}{\tau_{i g}}$

Assuming $\ell_{p}$ takes on the value $\ell_{p}(0)$ at $t=0$, the above equation has the exponential solution

$\ell_{p}(t)=\ell_{p}(0) \exp \left[t / \tau_{g}\right]$,

with a fire growth time constant, $\tau_{g}$, given by Eq. 5, followed by Eq. 2 upon substituting for $\dot{q}_{c h}^{\prime \prime}$

$\tau_{g}=\frac{\tau_{i g}}{\left[\frac{2 \dot{q}_{c h}^{\prime \prime}}{d \dot{q}_{c h}^{\prime \prime \prime}}-1\right]}=\frac{\tau_{i g}}{\left[\frac{2\left(\dot{q}_{f}^{\prime \prime}-\dot{q}_{0}^{\prime \prime}\right)}{d \dot{q}_{c h}^{\prime \prime \prime}} \frac{\Delta H_{c}}{\Delta H_{g}}-1\right]}$.

Ref. [16] gives an expression for net heat flux to the panels in the pyrolysis zone

$\dot{q}_{f}^{\prime \prime}-\dot{q}_{0}^{\prime \prime}=-\beta_{2} \dot{q}_{0}^{\prime \prime}+\frac{d \dot{q}_{c h}^{\prime \prime \prime} \varsigma_{f}(t)}{2}\left[\frac{\beta_{1}\left(Y_{s}+Y_{g}\right)^{1 / 4}}{\varsigma_{f}+\alpha \varsigma_{f}+\alpha}\right]$,

where $\varsigma_{f}(t)=\frac{\ell_{f}}{w}=\frac{\dot{Q}_{c h}(t)}{\dot{q}_{c h}^{\prime \prime \prime} d w^{2}}$ is the dimensionless flame height, $\alpha=d / w=0.5$ is the panel aspect ratio; and $Y_{s}$ and $Y_{g}$ are the fuel smoke yield and gas equivalent smoke yield (0.010), respectively; $\beta_{1}=$ radiation constant $=1.04$; and $\beta_{2}=$ heat loss constant $=1.7$. Here

$\dot{q}_{0}^{\prime \prime}=\varepsilon \sigma T_{i g}{ }^{4}\left(1-F_{s w \rightarrow s w}\right)=\dot{q}_{c r}^{\prime \prime}\left(1-F_{s w \rightarrow s w}\right)$

and the view factor between side wall to side wall $F_{s w \rightarrow s w} \cong 0.5$ for $\alpha=d / w=0.5$. Rearranging Eq. 8, one has

$\frac{2\left(\dot{q}_{f}^{\prime \prime}-\dot{q}_{0}^{\prime \prime}\right)}{d \dot{q}_{c h}^{\prime \prime}} \frac{\Delta H_{c}}{\Delta H_{g}}=\left\{\frac{-2 \beta_{2} \dot{q}_{0}^{\prime \prime}}{d \dot{q}_{c h}^{\prime \prime}}+\frac{\dot{Q}_{c h}(t)}{d w^{2} \dot{q}_{c h}^{\prime \prime \prime}}\left[\frac{\beta_{1}\left(Y_{s}+Y_{g}\right)^{1 / 4}}{\varsigma_{f}+\alpha \varsigma_{f}+\alpha}\right]\right\} \frac{\Delta H_{c}}{\Delta H_{g}}$

Then substituting the definition of $\varsigma_{f}(t)=\frac{\dot{Q}_{c h}(t)}{\dot{q}_{c h}^{\prime \prime} d w^{2}}$ and Eq. 10 into Eq. 7, one has

$\tau_{g}=\frac{\tau_{i g}}{\left[\left\{\frac{\beta_{1}\left(Y_{S}+Y_{g}\right)^{1 / 4} \varsigma_{f}}{\varsigma_{f}+\alpha \varsigma_{f}+\alpha}-\frac{2 \beta_{2} \dot{q}_{0}^{\prime \prime}}{\dot{q}_{c h}^{\prime \prime \prime} d}\right\} \frac{\Delta H_{c}}{\Delta H_{g}}-1\right]}$. 
The flame heat flux $\dot{q}_{f}^{\prime \prime}$ shown in Eq. 8 and the fire growth time $\tau_{g}$ shown in Eq. 11 both show a weak dependence on the flame height, $\varsigma_{f}$ which disappears asymptotically as $\varsigma_{f}$ becomes much larger than $\alpha /(1+\alpha)=1 / 3$. That is

$$
\tau_{g} \rightarrow \frac{\tau_{i g}}{\left[\left\{\frac{\beta_{1}\left(Y_{S}+Y_{g}\right)^{1 / 4}}{1+\alpha}-\frac{2 \beta_{2} \dot{q}_{0}^{\prime \prime}}{\dot{q}_{c h}^{\prime \prime \prime} d}\right\} \frac{\Delta H_{c}}{\Delta H_{g}}-1\right]} \text { for } \varsigma_{f}>>\alpha /(1+\alpha)
$$

Ref. [17] gives the ignition time $\tau_{g(t h i n)}$ including its moisture dependency for a thermally-thin corrugated paperboard as:

$$
\tau_{i g}=\frac{m^{\prime \prime} c_{0}\left(1+\gamma m_{w}\right)\left(T_{i g}-T_{0}\right)}{\dot{q}_{f}^{\prime \prime}-\dot{q}_{0}^{\prime \prime}}
$$

where, $m^{\prime \prime}$ is the mass of the dry corrugated per unit area; $c_{0}$ is the specific heat of the dry corrugated paperboard; $m_{w}$ is the fractional added mass of water in the sample (i.e., fractional moisture content); $\left(T_{i g}-T_{0}\right)$ is the pyrolysis temperature rise; and $\gamma=\frac{c_{p w}\left(T_{b}-T_{0}\right)+L_{w}}{c_{0}\left(T_{i g}-T_{0}\right)} \approx 5.0$ is the heat of gasification of water divided by the energy needed to ignite the dry corrugated. Thus, $\tau_{g}$ in Eq. 12 is proportional to the energy required for ignition.

\section{EXPERIMENTS}

\section{Parallel Panel Test}

The parallel panel tests were conducted for various types of corrugated paperboard samples, such as single wall, double wall and tri-wall.

Figure 2 shows the schematic of the $2.4 \mathrm{~m}$ high $\times 0.3 \mathrm{~m}$ wide parallel panel apparatus (PPA). The PPA consists of two identical frames, constructed of $3.2 \mathrm{~mm}$ thick, $3.8 \mathrm{~cm}$ wide steel angles that face each other. Plywood with a thickness of $12.7 \mathrm{~mm}$ was secured to the PPA frame and a piece of $19 \mathrm{~mm}$ thick Marinite I (calcium silicate) is secured to the plywood. Each sample type (one to three layers) was mounted on the Marinite I so that each panel faced the other across a $0.152 \mathrm{~m}$ gap. A propane sand burner, $0.305 \mathrm{~m}$ by $0.153 \mathrm{~m}$ and $0.305 \mathrm{~m}$ high was located below the panels. The top plane of the burner was held flush with the base of the parallel panels. Care was taken to ensure that air is entrained from the open sides of the PPA and not from the seams between the burner lip and the base of the panels. Propane was supplied at a constant flow rate of 10 SLM which corresponds to an approximate chemical heat release rate of $15 \mathrm{~kW}$. The entire PPA set-up was placed on a load cell platform $(1.8 \mathrm{~m} \times 1.8 \mathrm{~m})$ constructed of steel. Prior to initiating the fire test, a small sample was taken from the corrugated paperboard panels and the moisture content was measured (on a dry basis) by using a moisture analyzer. At the start of the test, the propane sand burner was lit and remained lit during the test. The chemical heat release rate (determined from the generation rates of $\mathrm{CO}$ and $\mathrm{CO}_{2}$ ) as well as the mass loss rate from the burning sample panels during the test were measured by a $1 \mathrm{MW}$ fire calorimeter located above the PPA.

One test was conducted to measure the heat flux generated between two parallel panels of tri-wall corrugated paperboard. Six Schmidt-Boelter heat flux gages were installed in order to obtain centerline heat flux measurements along the height of the panels. Five gages were installed on one panel and one gage was installed on the other. Five gages were located at heights of $0.13 \mathrm{~m}(0.42 \mathrm{ft}), 0.3 \mathrm{~m}(1 \mathrm{ft}), 0.6 \mathrm{~m}(2 \mathrm{ft}), 1.2 \mathrm{~m}$ $(4 \mathrm{ft})$ and $2.1 \mathrm{~m}(6.83 \mathrm{ft})$. The single gage on the other panel was located at $0.3 \mathrm{~m}(1 \mathrm{ft})$. Data from this gage and the one on the opposing wall indicated that both panels received about the same heat flux as a function of time. Each gage was inserted tightly into a hole (about the same diameter as the gage) such that the face of the gage was flush with the surface of the corrugated paperboard panel. The heat flux gages were 
supplied with cooling water at a temperature of $54.4^{\circ} \mathrm{C}\left(130^{\circ} \mathrm{F}\right)$. The reading from the heat flux gages used here are a measure of total heat transfer (convective and radiative).

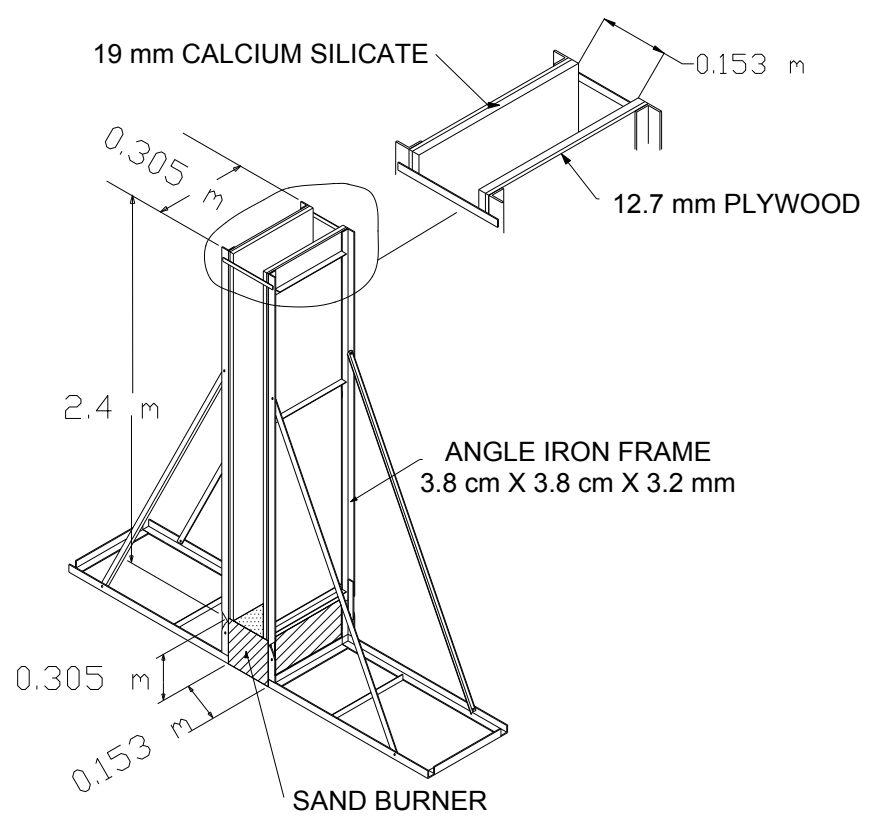

Figure Fig. 2. Schematic of parallel panel apparatus.

The flame height was determined by visual observations from a recorded digital video. It was observed that the flame height fluctuates. Therefore, the average flame height was assumed to be constant until it progresses to the next level of height. These incremental flame heights are shown in Fig. 3, where the trend-line is an approximation of the actual flame height as a function of time. The flame height was approximated up to $50 \mathrm{~s}$, at which point it reached its maximum.

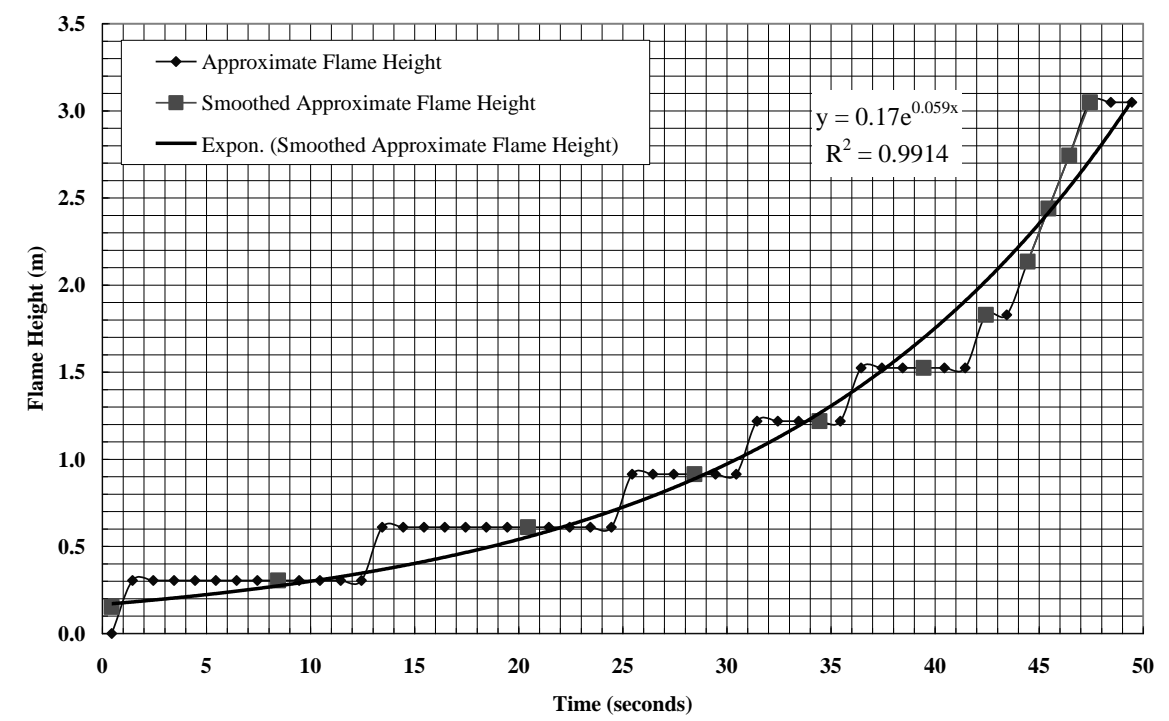

Fig. 3. Visual flame height vs. time for corrugated tri-wall paperboard in parallel panel apparatus experiment.

\section{Property Measurements}

All property measurements were conducted in the FPA. 


\section{Sample Preparation}

Circular samples $\left(9.53 \mathrm{~cm}\right.$ diameter, corresponding to a surface area of $\left.0.0071 \mathrm{~m}^{2}\right)$ in standard insulated sample holders [18] were conditioned in a vacuum oven at $105{ }^{\circ} \mathrm{C}$ for $24 \mathrm{~h}$ to completely remove moisture. Subsequently, these samples along with the sample holders were placed in a desiccator and transported to an environmental chamber for $24 \mathrm{~h}$ for conditioning at $23{ }^{\circ} \mathrm{C}$ and $50 \% \mathrm{RH}$. During the tests, the relative humidity of $50 \%$ was also maintained in the FPA with a humidity control and delivery system [17].

\section{Combustion Test}

For testing single wall, double wall and tri-wall samples, 5 layers, 3 layers and 2 layers, respectively, were placed in the sample holder. Each sample type with the sample holder was placed on the sample platform connected to a load cell (0-1000 g-range, $0.1 \mathrm{~g}$ accuracy, $20 \mathrm{mg}$ peak-to-peak noise), which continually recorded the sample weight during combustion process. A 19-point differential least squares slope technique was used to derive the mass loss rate data. Prior to the test, the sample surface was lightly coated with a uniform layer of carbon black $\left(160 \pm 5 \% \mathrm{~g} / \mathrm{m}^{2}\right)$. A pre-mixed, $10 \mathrm{~mm}$ long ethylene-oxygen pilot flame was positioned about $10 \mathrm{~mm}$ above and near the center of the top surface to ensure prompt ignition if sufficient fuel vapors were present. A quartz tube (162 $\mathrm{mm}$ ID and $431 \mathrm{~mm}$ long) was placed around the sample flowing normal air having a 200 SLM volume flow. A water cooled shield was used to protect the sample from exposure while the radiant heaters were brought to a specific heat flux setting. The samples were exposed to different levels of radiant heat flux, $50 \mathrm{~kW} / \mathrm{m}^{2}$ and $65 \mathrm{~kW} / \mathrm{m}^{2}$. In each test, after the ignition, the sample was allowed to burn completely and the measurements of chemical heat release rate (calculated from the generation rates of $\mathrm{CO}$ and $\mathrm{CO}_{2}$ ) and smoke generation rate as a function of time were made. The effective heat of combustion, $\Delta H_{c}(\mathrm{~kJ} / \mathrm{g})$ of the sample is calculated:

$$
\Delta H_{c}=\int_{t_{i}}^{t_{e x}} \dot{Q}_{c h} d t / \Delta m
$$

where, $\dot{Q}_{c h}$ is the chemical heat release rate $(\mathrm{kW}) ; t_{i}$ and $t_{e x}$ are the ignition and the flame out time, respectively; and $\Delta m$ is the total mass loss (g) during the time interval $t_{i}$ to $t_{e x}$. The effective heat of combustion data are presented for both values, tested at 50 and $65 \mathrm{~kW} / \mathrm{m}^{2}$ radiant fluxes, in Table 1 . The measurement accuracy [19] is $\pm 5 \%$. Similarly, the smoke yield, $Y_{s}$ is determined as follows:

$Y_{S}=\int_{t_{i}}^{t_{C x}} \dot{m}_{S} d t / \Delta m$

where, $\dot{m}_{s}$ is the generation rate of smoke $(\mathrm{g} / \mathrm{s})$. The smoke yield data are presented in Table 1. The measurement accuracy is $\pm 5 \%$.

\section{Pyrolysis Test}

Test conditions and sample preparation were the same as above. The test is conducted using the quartz tube (162 mm ID and $431 \mathrm{~mm}$ long) around the sample flowing $100 \% \mathrm{~N}_{2}$ with $100 \mathrm{SLM}$. The samples were exposed to radiant heat flux values of $20 \mathrm{~kW} / \mathrm{m}^{2}, 35 \mathrm{~kW} / \mathrm{m}^{2}, 50 \mathrm{~kW} / \mathrm{m}^{2}$ and $65 \mathrm{~kW} / \mathrm{m}^{2}$ and the mass loss rate as a function of time was measured for each test. These tests were conducted to determine the heat of gasification of the material. 


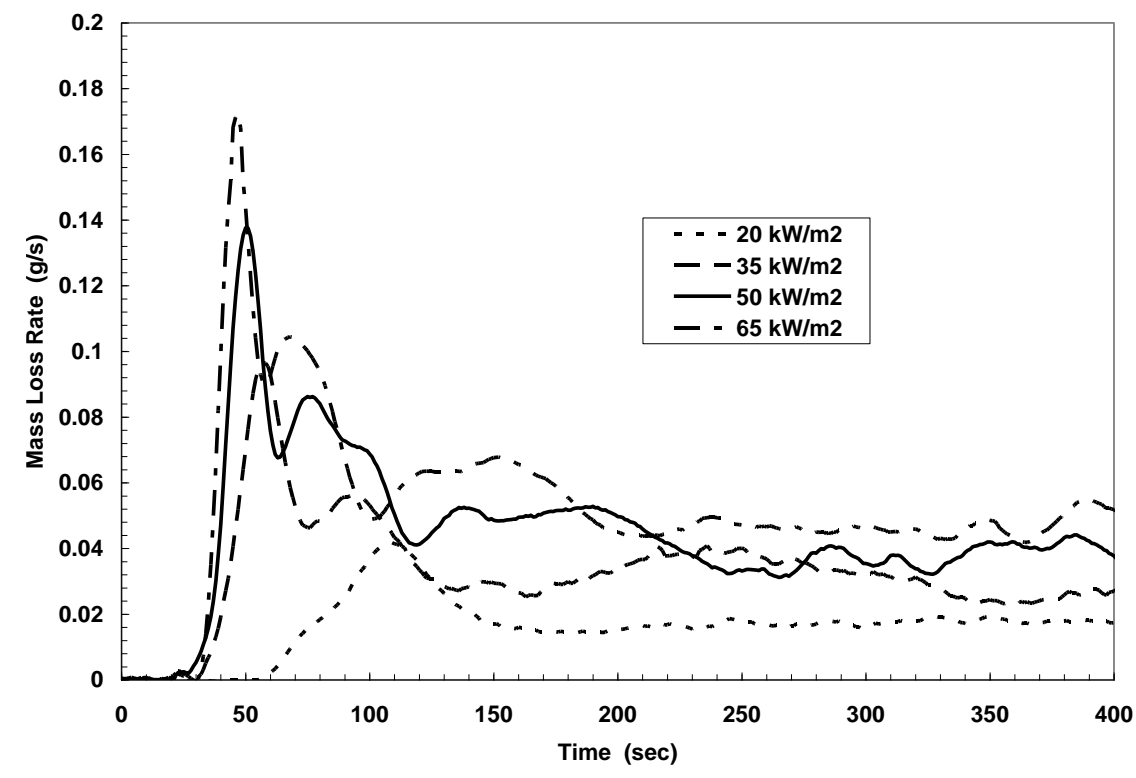

Fig. 4. Mass loss rate vs. time for double wall corrugated paperboard.

For example, the mass loss rate of a double-wall (3 layers) corrugated paperboard sample material subjected to several levels of radiant heat fluxes in an inert environment (in order to avoid the effect of flaming) is presented in Fig. 4. It can be seen in Fig. 4 that the initial gasification rate up to the peak is acceleratory followed by charring as the mass loss rate recedes rapidly. At a later stage, the sample delaminates as the inner layers get involved in the pyrolysis process. The rate of fire growth is driven by the peak mass loss rate corresponding to the minimum transient heat of gasification. The average heat of gasification is many times larger. Using the average heat of gasification would require an unrealistic increase in the flame heat transfer (i.e., coefficient $\beta_{1}$ in Eq. 12) to achieve fire growth. The peak mass loss rate per unit sample surface area prior to the initial char forming period is plotted as a function of radiant heat flux in Fig. 5. The inverse slope of the best fit regression line provides the heat of gasification of the material. The heat of gasification values for corrugated paperboard materials are listed in Table 1. These values are consistent with the values reported in the literature [20] for similar type of materials (filter paper: $3.6 \mathrm{~kJ} / \mathrm{g}$; wood Douglas-fir: $1.8 \mathrm{~kJ} / \mathrm{g}$; corrugated paperboard: $2.2 \mathrm{~kJ} / \mathrm{g}$ ). The measurement accuracy of mass loss rate is $\pm 5 \%$.

Table 1. Properties of corrugated paperboard samples measured in the FPA.

\begin{tabular}{|c|c|c|c|c|}
\hline Sample identification & $\begin{array}{l}\Delta H_{c}(\mathrm{~kJ} / \mathrm{g}) \\
50 \mathrm{~kW} / \mathrm{m}^{2}\end{array}$ & $\begin{array}{l}\Delta H_{c}(\mathrm{~kJ} / \mathrm{g}) \\
65 \mathrm{~kW} / \mathrm{m}^{2}\end{array}$ & $Y_{s}(\mathrm{~g} / \mathrm{g})$ & $\Delta H_{g}(\mathbf{k J} / \mathbf{g})$ \\
\hline Tri-wall (2 layers) & $13.0 \pm 0.7$ & $14.1 \pm 0.7$ & $0.011 \pm 0.0006$ & $2.3,2.4$ (repeat) \\
\hline Double wall (3 layers) & $13.0 \pm 0.7$ & $14.4 \pm 0.7$ & $0.013 \pm 0.0007$ & 2.4 \\
\hline Single wall (5 layers) & $15.7 \pm 0.8$ & $15.8 \pm 0.8$ & $0.011 \pm 0.0006$ & 3.0 \\
\hline Single wall (5 layers) & $15.7 \pm 0.8$ & $15.8 \pm 0.8$ & $0.012 \pm 0.0006$ & 3.2 \\
\hline
\end{tabular}




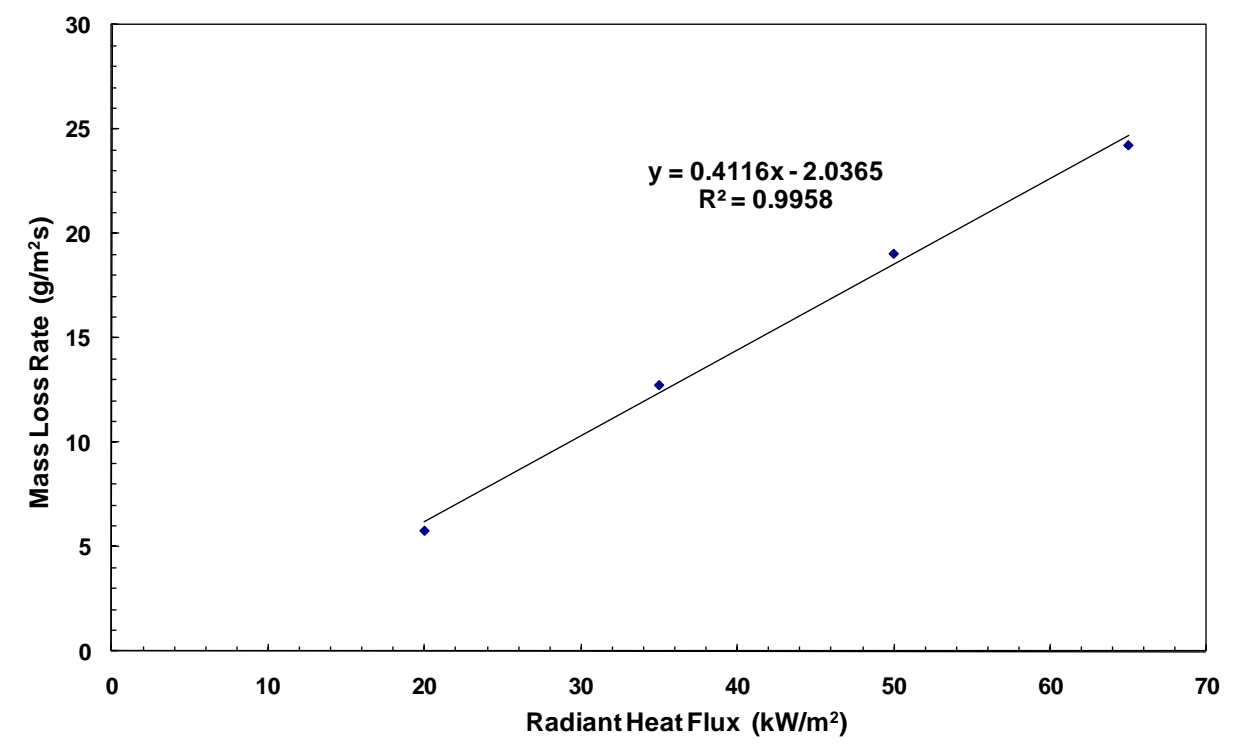

Fig. 5. Mass loss rate per unit area vs. incident radiant flux for double wall corrugated paperboard.

\section{Critical Heat Flux Measurement}

Test conditions and sample preparation were the same as for the combustion test. A single layer of corrugated paperboard sample with the insulated sample holder [18] was placed on the sample platform. The samples were exposed to several values of radiant heat fluxes, and the times to piloted ignition were recorded.

The critical heat flux for ignition, $\dot{q}_{c r}^{\prime \prime}$ is determined by plotting the inverse of the time to ignition versus the radiant heat fluxes between $10 \mathrm{~kW} / \mathrm{m}^{2}$ and $20 \mathrm{~kW} / \mathrm{m}^{2}$ (measured in the FPA), for which the ignition times are very large. The intercept of a straight-line regression fit with the abscissa provides the critical flux corresponding to an infinite ignition time. Table 2 presents the critical heat flux values for some corrugated paper board samples. The standard deviation of the critical heat flux intercept is also presented in Table 2.

Table 2. Critical heat flux for corrugated paperboard samples.

\begin{tabular}{|c|c|c|}
\hline Sample identification & $\begin{array}{c}\text { Critical heat flux }(\mathbf{C H F}) \\
\left(\mathbf{k W / \mathbf { m } ^ { 2 }}\right)\end{array}$ & $\begin{array}{c}\text { Standard deviation of } \\
\text { CHF intercept }\left(\mathbf{k W} / \mathbf{m}^{\mathbf{2}}\right)\end{array}$ \\
\hline Single wall & 8.4 & 1.1 \\
\hline Single wall & 8.1 & 0.8 \\
\hline Single wall & 8.2 & 1.0 \\
\hline Double wall & 8.1 & 0.8 \\
\hline Tri-wall & 9.0 & 1.2 \\
\hline
\end{tabular}

for each material. Note that for single wall material, three CHF tests were conducted for evaluating repeatability. The critical heat flux values as found in this study are comparable to our previously reported [17] measurements.

\section{RESULTS AND DISCUSSION}

\section{Exponential Fire Growth}

Figure 6 presents the heat flux measurements at different heights $(0.13 \mathrm{~m}, 0.305 \mathrm{~m}, 0.61 \mathrm{~m}, 1.22 \mathrm{~m}$ and $2.08 \mathrm{~m}$ ) of the panel as a function of time. As mentioned in the experimental section, the average data of the two heat flux gages located at the same $0.305 \mathrm{~m}$ height of the two parallel panels is presented here. We have also included the approximate flame height, exponentially increasing as a function of time, previously shown in Fig. 3. 


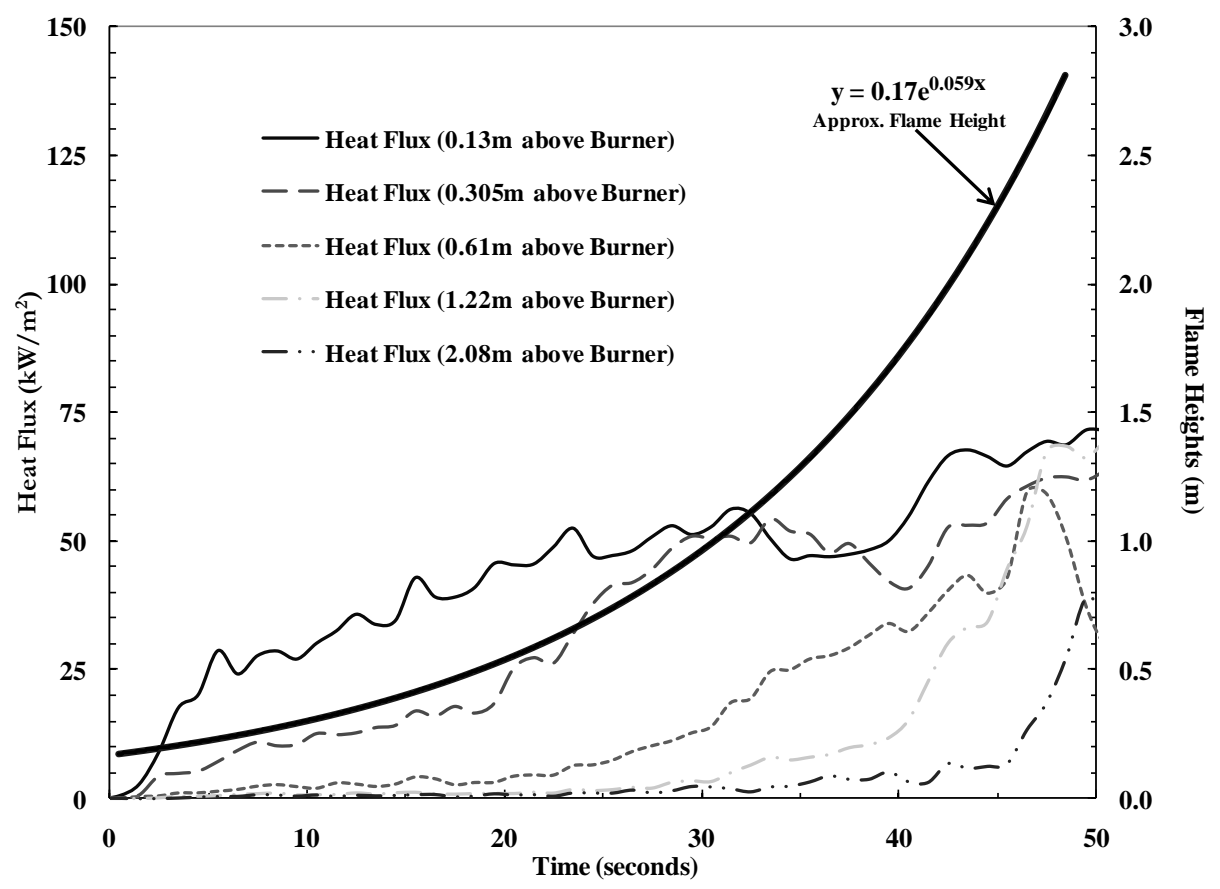

Fig. 6. Heat flux for parallel panel of tri-wall corrugated paperboard as a function of time.

The heat flux, in the time period when the flame height increased to the top of the panels, was within approximately $30-60 \mathrm{~kW} / \mathrm{m}^{2}$ at the $1.22 \mathrm{~m}$ height. The asymptotic flame heat flux $\dot{q}_{f}^{\prime \prime}$ was $40 \mathrm{~kW} / \mathrm{m}^{2}$ given by model Eq. 12. It has been shown that for heat fluxes up to $50 \mathrm{~kW} / \mathrm{m}^{2}$ corrugated paperboard behaves as a thermally-thin solid at ignition [17]. During this period, experimentally measured exponential fire growth in terms of chemical heat release rate as a function of time, shown in Fig. 7, is at its peak value. In all cases, evaluation of the exponential fire growth constant, $\tau_{g_{\text {exxp }}}$ was initiated when the chemical heat release rate was approximately $10 \mathrm{~kW}$ and terminated just prior to the peak value when obviously the exponential growth ceased. The $\tau_{g_{-} \text {exp }}$ for single, double and tri-wall corrugated paperboard samples as determined from the curves are presented in Fig. 7.

\section{Fire Growth Time Constant}

To calculate the exponential fire growth time constant, the analytic model Eq. 12 and Eq. 13 (for thermallythin conditions) were used with the measured properties $\Delta H_{c}, \Delta H_{g}, \dot{q}_{c r}^{\prime \prime}$ and $Y_{s}$ listed in Table 1 and Table 2. The properties, $m^{\prime \prime}, T_{i g}$ and $c_{0}$ are taken from Ref. [17] and are listed in Table 3 below. One also needs for the model the fractional moisture content, $m_{w}$, given in Table 4.

Table 3. Corrugated paperboard properties.

\begin{tabular}{|l|l|l|}
\hline$m^{\prime \prime}$ single wall & 0.46 & $\mathrm{~kg} / \mathrm{m}^{2}$ \\
\hline$m^{\prime \prime}$ double wall & 0.58 & $\mathrm{~kg} / \mathrm{m}^{2}$ \\
\hline$m^{\prime \prime}$ tri-wall & 0.66 & $\mathrm{~kg} / \mathrm{m}^{2}$ \\
\hline$T_{i g}$ & 625 & $\mathrm{~K}$ \\
\hline$T_{0}$ & 298.15 & $\mathrm{~K}$ \\
\hline$c_{0}$ & 1.52 & $\mathrm{~kJ} / \mathrm{kg} \cdot \mathrm{K}$ \\
\hline
\end{tabular}




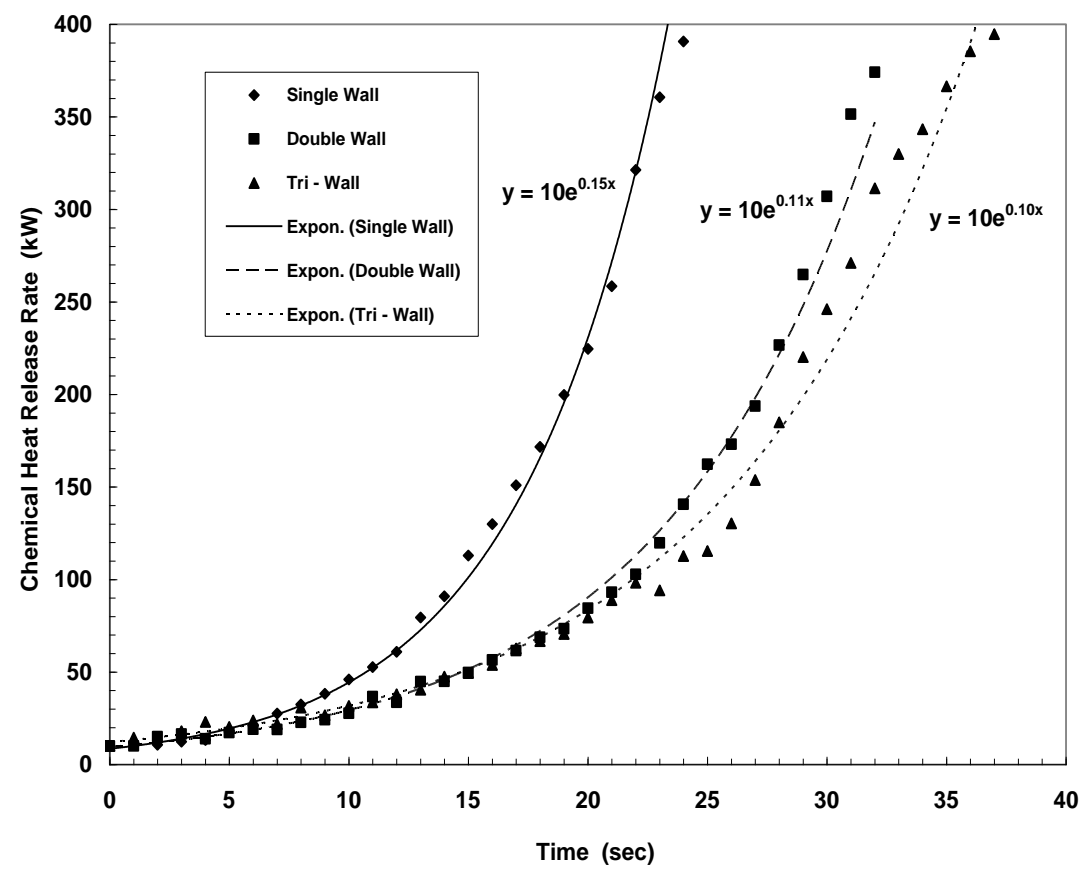

Fig. 7. Chemical heat release rate vs. time for corrugated paperboard samples in parallel panel experiments.

The model calculations of $\tau_{g_{-} \text {cal }}$ are presented in Table 4 for all the samples examined in this study. The experimental values of fire growth time constants, $\tau_{g_{\text {_exp }}}$ from the experimental fits shown in Fig. 7, are also listed in Table 4 (ranges are given for repeat tests). In all cases, $\tau_{g_{-} c a l}$ was determined by setting the $m_{w}$ value the same as the experimental moisture content as reported in Table 4 (column 2).

The constants $\beta_{1}=1.04$ and $\beta_{2}=1.7$ from the original heat transfer model, Ref. [16], were fitted to flame heat transfer measurements obtained from a larger parallel panel apparatus for which radiative heat transfer was dominant. However, the separation distance, $d$ for the current study is only half as large $(0.153 \mathrm{~m})$ resulting in proportionately less radiative heat transfer and an enhanced role for convective heat transfer. By increasing $\beta_{1}$ from 1.04 to 1.82 , the model adequately predicts the $\tau_{g_{-} \text {cal }}$. This choice increases the total flame heat transfer to values more closely approximating the measurements shown in Fig. 6 and was used for calculating $\tau_{g_{-} \text {cal }}$ in Table 4, below.

Table 4. Fire growth time constants - experiment vs. model.

\begin{tabular}{|c|c|c|c|}
\hline Sample description & $\begin{array}{c}\text { Moisture content } \\
\text { (pre-test) } \mathbf{( \% )}\end{array}$ & $\begin{array}{c}\tau_{g_{\text {e }} \text { exp }} \\
\text { (s) range }\end{array}$ & $\begin{array}{c}\tau_{g_{\text {c }} \text { cal }} \\
\text { (s) range }\end{array}$ \\
\hline Tri-wall (2 layers) & $9.0 \pm 0.5$ & $9.7-12.7$ & $10.0-12.5$ \\
\hline Tri-wall (2 layers) & $9.5 \pm 0.5$ & 10.8 & 10.0 \\
\hline Tri-wall (2 layers) & $8.7 \pm 0.5$ & 8.3 & 10.0 \\
\hline Tri-wall (2 layers) & $8.2 \pm 0.5$ & 8.9 & 10.1 \\
\hline Tri-wall (2 layers) & $8.5 \pm 0.5$ & 10.9 & 10.1 \\
\hline Double wall (3 layers) & - & $8.4-9.5$ & $8.9-9.0$ \\
\hline Double wall (3 layers) & $8.6 \pm 0.5$ & 11.2 & 11.0 \\
\hline Double wall (3 layers) & $7.2 \pm 0.5$ & 10.5 & 10.5 \\
\hline Double wall (3 layers) & $8.9 \pm 0.5$ & 10.9 & 11.2 \\
\hline Single wall (1 layer) & $9.0 \pm 0.5$ & 8.9 & 9.4 \\
\hline Single wall (1 layer) & - & $6.6-6.7$ & $8.6-8.6$ \\
\hline Single wall (1 layer) & $6.9 \pm 0.5$ & 7.3 & 8.6 \\
\hline Single wall (1 layer) & $9.4 \pm 0.5$ & 8.8 & 9.5 \\
\hline Single wall (1 layer) & $8.8 \pm 0.5$ & 7.7 & 9.3 \\
\hline Single wall (1 layer) & $9.0 \pm 0.5$ & 8.2 & 9.4 \\
\hline
\end{tabular}


All the data for both $\tau_{g_{-} c a l}$ and $\tau_{g_{-} \text {exp }}$ in Table 4 are plotted in Fig. 8. The figure shows satisfactory agreement of the model with the experimental data.

\section{Effects of Corrugated Paperboard Properties on $\tau_{g_{-} c a l}$}

It is quite difficult to conduct parallel panel tests with varying $m_{w}$ (fractional moisture content) in order to assess its impact on $\tau_{g_{-} \text {exp. }}$. However, one can assess the role of moisture by using the current model. By changing $m_{w}$ in the model from 0.04 to 0.08 (equilibrium values corresponding to $20 \%$ and $60 \% \mathrm{RH}$ ) [17], $\tau_{g_{-} \text {cal }}$ increases about $15 \%$ (see Fig. 9).

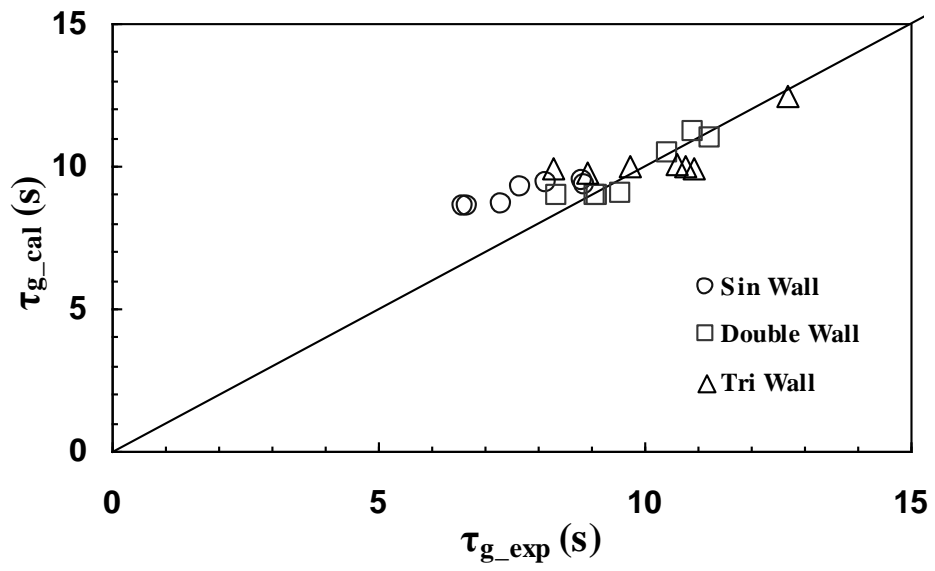

Fig. 8. Measured $\tau_{g_{-} \exp }$ vs. calculated $\tau_{g_{-} \text {cal }}$.

The impact of a change in linerboard materials in terms of $m^{\prime \prime}$ (mass of dry corrugated paperboard per unit area, i.e., areal density) [17] on $\tau_{g_{-} c a l}$ is also presented in Fig. 9. Keeping $m_{w}$ constant, if mass of dry corrugated per unit area is doubled from 0.33 to $0.66 \mathrm{~kg} / \mathrm{m}^{2}, \tau_{g_{-} \text {cal }}$ increases significantly, doubling as well.

For typical corrugated paperboard materials, the model says that a $5 \%$ variation of the heats of combustion and gasification results in an $8 \%$ variation in $\tau_{g_{-} c a l}$. Whereas a $5 \%$ variation in critical heat flux and smoke yield result in only a $2.5 \%$ variation in $\tau_{g_{-} \text {cal }}$. Finally $\tau_{g_{-} \text {cal }}$ is proportional to the energy required for ignition.

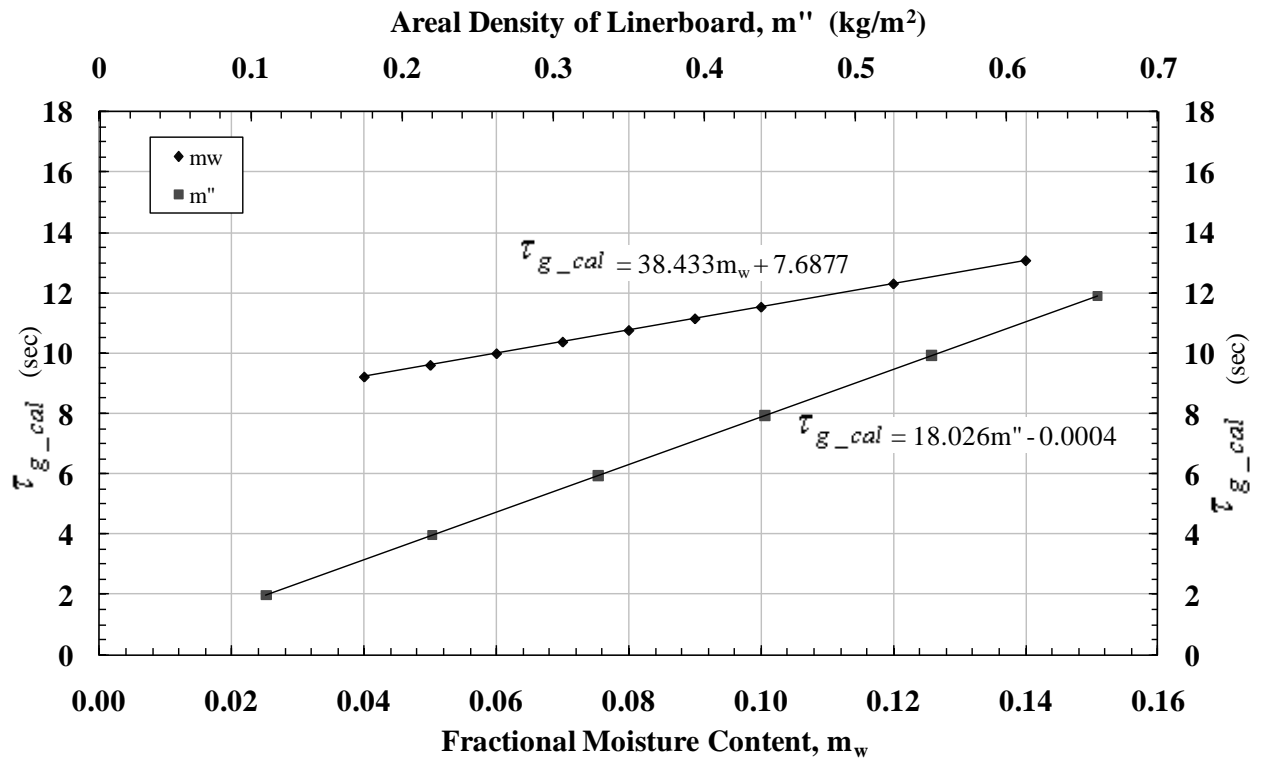

Fig. 9. The effects of $m_{w}$ and $m^{\prime \prime}$ on $\tau_{g_{-} c a l}$. 


\section{CONCLUSIONS}

Upward fire growth along vertical corrugated paperboard samples placed parallel (size of each sample: $0.305 \mathrm{~m} \times 2.4 \mathrm{~m}$ ) and facing each other (about $0.153 \mathrm{~m}$ apart) was measured in terms of chemical heat release rate as a function of time. A $15 \mathrm{~kW}$ propane sand burner was used at the base as an ignition source. In all cases, the samples exhibited exponential fire growth rates.

A simple analytic fire growth model was developed. By using one parameter determined from comparison with experimental data $\left(\beta_{1}=1.82\right)$ the model gives reasonable prediction of the exponential fire growth time constant $\tau_{g_{\text {_cal }} \text {. }}$ The effect of moisture on fire growth rate is incorporated in the model. The model needs input properties, such as the heat of combustion, minimum heat of gasification, yield of smoke, and critical heat flux, which are all routinely obtained from the Fire Propagation Apparatus. Using an average heat of gasification, instead of the minimum heat of gasification, would require an unrealistic increase in the flame heat transfer (coefficient $\beta_{1}$ ) to achieve fire growth. The model prediction of exponential fire growth time constant agrees reasonably well with the experimentally determined values.

The model shows that doubling the linerboard weight slows the propagation rate by a factor of two. The model also shows that changing the moisture content from $4 \%$ to $8 \%$ (corresponding to $20 \%$ to $60 \% \mathrm{RH}$ ) increases the growth time constant by $15 \%$. For typical corrugated paperboard materials, the model indicates that a $5 \%$ variation of the heats of combustion and gasification results in an $8 \%$ variation in $\tau_{g_{-} c a l}$, whereas a $5 \%$ variation in critical heat flux and smoke yield result in only a $2.5 \%$ variation in $\tau_{g_{-}}$cal . Finally $\tau_{g_{-} c a l}$ is proportional to the energy required for ignition.

\section{ACKNOWLEDGEMENTS}

The authors wish to acknowledge contributions by Stephen Ogden and Stephen D'Aniello. The work presented in this paper was performed within the framework of the FM Global Research Program on Flammability Technology, which is internally funded. The encouragement of Dr Sergey B. Dorofeev and Dr Robert G. Bill throughout the course of this study is gratefully acknowledged.

\section{REFERENCES}

[1] Orloff, L., de Ris, J. L., and Markstein, G. H., "Upward Turbulent Fire Spread and Burning of Fuel Surfaces," Proceedings of the Combustion Institute, Vol. 15, pp. 183-192, (1974).

[2] Quintiere, J.G., Harkleroad, M., and Hasemi, Y., (1986) Wall Flames and Implications for Upward Flame Spread, Combustion Science and Technology, 48: 191-222, http://dx.doi.org/10.1080/00102208608923893.

[3] Saito, K., Quintiere, J.G. and Williams, F.A., 1986. Upward Turbulent Flame Spread. Fire Safety Science 1: 75-86. http://dx.doi.org/10.3801/IAFSS.FSS.1-75

[4] Dillon, S.E., Quintiere, J.G. and Kim, W.H., 2000. Discussion of a Model and Correlation for the ISO 9705 Room-corner Test. Fire Safety Science 6: 1015-1026. http://dx.doi.org/10.3801/IAFSS.FSS.6-1015

[5] Karlsson, B., (1994) Models for Calculating Flame Spread on Wall Lining Materials and the Resulting Heat Release Rate in a Room, Fire Safety Journal, Vol. 23: 365-386, http://dx.doi.org/10.1016/0379-7112(94)90004-3

[6] Mowrer, F.W. and Williamson, R.B., 1991. Flame Spread Evaluation for Thin Interior Finish Materials. Fire Safety Science 3: 689-698. http://dx.doi.org/10.3801/IAFSS.FSS.3-689

[7] Williams, F.W., Beyler, C.L., Hunt, S.P., and Iqbal, N., "Upward Flame Spread on Vertical Surfaces," Series Report, NRL/MR/6180-97-7908, Naval Research Lab., Washington, D.C., January 13, 1997, U.S. Department of Commerce, National Technical Information Service.

[8] Alpert, R. L., "The Role of Radiation in Pressure Modeling of Upward Fire Spread," ASME Paper No. 79- HT-28, 1980. 
[9] Karlsson, B., "Mathematical Models for Calculating Heat Release Rate in the Room Corner Test," Fire and Flammability of Furnishings and Contents of Buildings, ASTM STP 1233, A.J. Fowell, Ed., pp.216-236, 1994, http://dx.doi.org/10.1520/STP12959S

[10] Heskestad, G., "Similarity Relations for the Initial Convective Flow Generated by Fire," ASME Paper No. 72-WA/HT-17 (November 1972).

[11] Khan, M.M., Alpert, R.L., and Smith, G.A., "Fire Tests for Non-Melting Plastic Rooflight Materials," Roofing Research and Standards Development: $5^{\text {th }}$ Volume, ASTM STP 1451, W.J. Rossiter and T.J. Wallace, Eds., ASTM International, West Conshohocken, PA, 2003, http://dx.doi.org/10.1520/STP11448S.

[12] FM Global Open Source CFD Fire Modeling Workshop, available at http://sites.google.com/site/firemodelingworkshop/

[13] ANSI/FM Approval Standard 4910, American National Standard for Cleanroom Materials Flammability Test Protocol, FM Approval, Norwood, MA, June 2004.

[14] Krishnamoorthy, N, Chaos, M., Khan, M.M., Chatterjee, P., Wang, Y., and Dorofeev, S.B., "Application of Bench-Scale Material Flammability Data to Model Flame Spread in IntermediateScale Parallel Panel Test," Conference Proceedings, Vol 1, $12^{\text {th }}$ International Fire Science \& Engineering Conference, Interflam 2010.

[15] Chaos, M., Khan, M.M., Krishnamoorthy, N., de Ris, J.L. and Dorofeev, S.B., "Evaluation of Optimization Schemes and Determination of Solid Fuel Properties for CFD Fire Models Using Bench-Scale Pyrolysis Tests," Proceedings of the Combustion Institute 33 (2011) 2599-2606, http://dx.doi.org/10.1016/j.proci.2010.07.018

[16] De Ris, J.L. and Orloff, L., 2005. Flame Heat Transfer between Parallel Panels. Fire Safety Science 8: 999-1010. http://dx.doi.org/10.3801/IAFSS.FSS.8-999

[17] Khan, M.M., De Ris, J.L. and Ogden, S.D., 2009. Effect of Moisture on Ignition Time of Cellulosic Materials. Fire Safety Science 9: 167-178. http://dx.doi.org/10.3801/IAFSS.FSS.9-167

[18] de Ris, J.L. and Khan, M.M., (2000) A Sample Holder for Determining Material Properties, Fire and Materials, 24: 219-229, http://dx.doi.org/10.1002/1099-1018(200009/10)24:5\%3C219::AIDFAM741\%3E3.0.CO;2-7.

[19] Khan, M.M. and Bill, R.G., (2003) Comparison of Flammability Measurements in Vertical and Horizontal Exhaust Duct in the ASTM E-2058 Fire Propagation Apparatus, Fire and Materials, 27: 253-266, http://dx.doi.org/10.1002/fam.830.

[20] Tewarson, A., "Generation of Heat and Chemical Compounds in Fires," Chapter 4, Section 3, The SFPE Handbook of Fire Protection Engineering, $3^{\text {rd }}$ ed., pp. 3-82 to 3-161, The National Fire Protection Association Press, Quincy, MA 2002. 